\title{
Return to Sport Following Anterior Cruciate Ligament RECOnSTRUCTION: Women’s Lacrosse
}

\author{
Rachel E. Lampros, PT, DPT, SCS, MS ${ }^{1}$, Isabella Sprague, PT, DPT, SCS ${ }^{1}$ \\ ${ }^{1}$ Massachusetts General Hospital Sports Physical Therapy, Boston, Massachusetts USA
}

Participation in women's lacrosse has increased in popularity over the last 20 years with a subsequent rise in sports-related injuries. Despite this increase, there is a paucity of research examining this population, particularly regarding guidelines for safe return to lacrosse after anterior cruciate ligament (ACL) reconstruction. A lacrosse-specific functional rehabilitation program is critical to the success of the athlete. The athlete must be prepared and demonstrate the ability to cut, pivot, jump, pass, and shoot with the incidental contact required for sport clearance. A criterion-based program delineating a progression of range of motion, mobility, strength, neuromuscular control, agility, and cardiovascular training is an essential part of ACL rehabilitation. Early incorporation of lacrosse-specific skills emphasizing multiplanar neuromuscular control should gradually progress to more challenging field-based tasks as the athlete transitions through their rehabilitation program. A multidisciplinary team of physicians, physical therapists, athletic trainers, strength and conditioning specialists, coaches, and parents must collaborate effectively to reduce the athlete's risk for reinjury, meet the demands of the sport, and facilitate returning to the field without complications.

According to the US lacrosse annual participation survey, lacrosse has been "the fastestgrowing team sport in the nation at the high-school level for at least the last two decades."1-7 Women's lacrosse has gained tremendous popularity with a $25.7 \%$ increase in schools sponsoring girls' programs from 2013 to 2018.7 This rapid growth in participation has led to an increase in lacrossespecific injuries and a subsequent need for clinicians to familiarize themselves with the sport, tailoring their treatment strategies accordingly.

Women's lacrosse is a team sport with a unique set of rules and equipment compared to other field sports. It is played with a total of twelve players on each team: one goalie, three defenders, five midfielders, and three attackers. Each player has a stick made up of a long shaft and a shallow mesh pocket. Players cradle a hard rubber ball in the pocket, passing and shooting the ball trying to score on the opposing team. ${ }^{8}$

There are several important demarcations on the field that impact the trajectory of the game. The crease encircles the net and only the goalie or other defensive players are allowed to enter this area. Offensive players are allowed to move the ball behind the net and can "roll the crease" forcefully pivoting around the crease for passing and scoring opportunities. ${ }^{8}$

The eight-meter arc is a fan-shaped line and is considered a critical scoring area. Defensive players are only allowed inside the 8-meter area for 3 seconds if not within one stick-length of a player from the opposing team. ${ }^{8}$ This is analogous to the key in basketball. Players are tasked with dodging defensive players, passing on the run, and shooting at high speeds through heavily trafficked spaces.

It is important for clinicians working with this population to appreciate the fast-paced nature of the sport and the quick changes in speed and direction executed during competition. The dexterity required to handle the stick and maintain possession of the ball while performing these activities involves a tremendous amount of coordination and skill. 
Women's lacrosse, unlike its male counterpart, is a non-contact sport. No intentional contact is allowed including body checking, stick checking to the head, slashing, or dangerous propulsion of the ball. However, incidental contact is common because stick checking and defensive on-ball contact is permitted when performed in a controlled manner. Women also play on a slightly larger field with two additional players, they play with a shallower pocket, the shaft length is the same regardless of position, and they wear minimal protective equipment including a mouth guard and goggles. ${ }^{8}$

Due to the high-speed and physical nature of the game, injuries are common. ${ }^{1,9}$ Several descriptive epidemiological studies have been performed to identify patterns of injury.10-14 Knee ligament injuries are among the most common for female high-school and college players. ${ }^{15-19}$ More specifically, anterior cruciate ligament (ACL) injury incidence ranges between .18 and .25 .15

The most common injury mechanism occurs while cutting and pivoting during non-contact play. ${ }^{1,10,11}$ Carter et al found body-to-body and stick-to-body injuries were also quite common..$^{20}$ Game injury rates were twice as high as practice injury rates for both high-school and collegiate players. $9,11,17$

Dick et al found that players handling the ball had a higher incidence of injury and nearly half of these injuries were non-contact and occurred inside the 8-meter arc. ${ }^{11}$ Furthermore, an important finding by Barber Foss et al was that offensive players had the most injuries when compared to midfielders, defenders, and goalies. ${ }^{10}$ These reviews suggest that increased possession of the ball may increase the players' overall risk for injury.

Several studies have demonstrated an increase in ACL injury incidence in women's sports compared to their male counterparts, but this has not been consistently demonstrated in lacrosse. ${ }^{13,21-}$ 23 Agel et al presented data on the rate of ACL injuries in 15 collegiate sports from 2004 to 2013 and found that women sustained ACL injuries at higher rates than men in the sports of soccer, basketball, and lacrosse. Lacrosse was also found to have the highest average annual rate of ACL injury for women's sports. ${ }^{15}$ Mihata and Prodromos however, determined the incidence of ACL injuries was actually equal between genders..$^{24,25}$
Structured return to sport (RTS) programs are highly recommended in the literature but the optimal set of clinical criteria utilized to determine readiness to RTS are highly variable. ${ }^{1-6,26}$ Time from surgery has repeatedly been reported as the most used criteria for return to sport clearance however, physiologic healing timelines alone have consistently failed to identify safe RTS without risk of secondary injury. 27,28 Testing of strength, neuromuscular control, agility, and psychological readiness have emerged as more critical measures for RTS in younger athletes. ${ }^{1-6,28-32}$

While numerous clinical guidelines for physical therapy after ACL reconstruction exist in the literature, ${ }^{1-6,28-30,32}$ very few of these explicitly detail late phase RTS suggestions. ${ }^{33-36}$ Despite repeated studies profiling the high-risk for ACL injuries in women's lacrosse, there is minimal literature available to support the management of this population. Furthermore, research demonstrating the effectiveness of sports-specific programs is lacking.

Rehabilitation guidelines addressing lacrossespecific injuries must include targeted exercises emphasizing neuromuscular control and dynamic stability. There are several mechanical stresses unique to women's lacrosse such as throwing, shooting, dodging, running with the stick, and jump landings. Lumbopelvic, hip, and trunk control must be prioritized in these programs to meet the intricacies of the sport. Multiplanar training emphasizing velocity, power, and coordination is necessary to adequately prepare these athletes for RTS. ${ }^{37}$

\section{SPORT-SPECIFIC REHABILITATION PHASES}

Standard rehabilitation may be divided into five main phases, from early post-operative management to late phase RTS guidance. These phases focus on criterion-based progressions to help standardize care, optimize outcomes, and calibrate realistic patient expectations. The purpose of this manuscript is to discuss late phase rehabilitation and help guide clinicians toward optimal treatment for the female lacrosse player. There is little specialization in early post-operative management due to the acuity of the individual. Therefore, Phases 1 and 2 will briefly discuss lacrosse-specific considerations but this article will focus primarily on Phases 3 through 5 . 
Table 1a. Rehabilitation Protocol for Phase 1 and 2

Phase 1

Phase 2

\begin{tabular}{|c|c|c|}
\hline $\begin{array}{r}\text { Optimal Time } \\
\text { Frame }\end{array}$ & 0-6 weeks & 6-12 weeks \\
\hline Criteria to Progress & $\begin{array}{l}\text { Achieve full extension } \\
\text { Achieve flexion }>130 \text { degrees } \\
\text { Patellar mobility } 3 / 6 \text { in all planes } \\
\text { - Trace to no suprapatellar effusion } \\
\text { - Normal gait mechanics } \\
\text { - Ready to initiate single leg } \\
\text { strengthening }\end{array}$ & $\begin{array}{l}\text { Quadriceps LSI }>65 \% \text { by } 8 \text { weeks } \\
\text { and }>80 \% \text { by end of phase } \\
\text { - Hip Abductor LSI }>80 \% \\
\text { - Hamstring LSI }>70 / 80 \% \\
\text { (depending on graft site or } \\
\text { concomitant procedures) } \\
\text { - Good neuromuscular control with } \\
60 \text {-second timed step-down test }\end{array}$ \\
\hline $\begin{array}{r}\text { Exercise } \\
\text { Recommendations }\end{array}$ & $\begin{array}{l}\text { Progressive quadriceps, hamstring, } \\
\text { gluteal Strengthening } \\
\text { DL to SL balance and proprioceptive } \\
\text { drills } \\
\text { Lumbopelvic/core stabilization } \\
\text { exercises }\end{array}$ & $\begin{array}{l}\text { - Progressive resisted SL } \\
\text { strengthening } \\
\text { - Progress SL balance exercises to } \\
\text { simple/complex SL perturbation } \\
\text { training }\end{array}$ \\
\hline $\begin{array}{r}\text { Cardiovascular } \\
\text { Recommendations }\end{array}$ & $\begin{array}{l}\text { Stationary bike with minimal to no } \\
\text { resistance, } 20-30 \text { minutes daily } \\
\text { Upper body ergometer } \\
\text { Airdyne }^{\circledR} \text { bike with arms only }\end{array}$ & $\begin{array}{l}\text { Stationary bike with moderate } \\
\text { resistance, } 30-45 \text { minutes } \\
\text {. Elliptical training beginning at } 8 \\
\text { weeks }\end{array}$ \\
\hline Pool Program & $\begin{array}{l}\text { Gait training at } 4 \text { weeks or once } \\
\text { incisions healed }\end{array}$ & $\begin{array}{l}\text { Kick board with straight leg } \\
\text { kicking } \\
\text {. Aqua jogging 10-20 minutes }\end{array}$ \\
\hline
\end{tabular}

(DL, double leg; SL, single leg; LSI, limb symmetry index)

\section{PHASE 1: PROTECTION AND MOBILITY}

Phase 1 treatment should focus on edema control, pain management, range of motion, patella mobility, and quadriceps activation. Surgeon preference, graft type, and presence of concomitant procedures will dictate individual precautions and contraindications. Refer to Table 1a for further guidance.

\section{Suggested Rehabilitation Program for Phase 1:}

Athletes who achieve their range of motion, swelling, and strength goals with ease can begin lacrosse-specific training at the end of Phase 1. Initiating targeted transverse plan strengthening is critical to meet the physical demands of the sport.

Balance and Proprioception:

Once the patient demonstrates adequate strength and control, she can begin balance and proprioceptive training. Athletes can begin gentle cradling and stick handling drills during tandem or single limb stance exercises to foster improvements in neuromuscular control.

Lumbopelvic/Core Strengthening:

Appropriate Phase 1 exercises include tall plank, stability press with resistance band, dead bugs, and mini squats with a unilateral row.

Criteria to Progress to Phase 2: See Table 1a.

\section{PHASE 2: STRENGTHENING}

Phase 2 is primarily focused on building strength and addressing limitations in neuromuscular control. For the female lacrosse player, additional emphasis should be placed on upper extremity and dynamic lumbopelvic strengthening to prepare for catching and throwing. Special attention should be placed on fostering adequate trunk control and upper extremity strength while performing more difficult lower extremity tasks. 


\section{Suggested Rehabilitation Program for Phase 2: \\ Balance and Proprioception:}

Balance exercises should progress to single leg variations and incorporate unstable surfaces and perturbation training. These exercises should be performed in conjunction with stick handling drills. Gentle cradling should progress to switching hands, adding fakes, cross body, one-handed, and high to low cradling to create subtle deviations in the player's trunk control. Graded on-body perturbations or rhythmic stability drills using her stick should also be considered to promote improved neuromuscular control and emulate future game-like contact.

\section{Lumbopelvic/core Strengthening:}

These exercises should advance in this phase with continued emphasis on coordination, stability, and strength. Bird dogs, mountain climbers, "supermans," side plank with clamshell, and inverted row variations are appropriate during this phase. Throwing and catching a medicine ball in a double limb or single limb squat with a rebounder can also be introduced to mirror the physiologic demands of catching and throwing.

Preparation for Throwing:

Upper extremity strengthening to prepare for throwing should also be included 2-3 times a week. Exercises to consider include prone horizontal abduction, prone horizontal with full external rotation and abduction to 100 degrees, resisted internal and external rotation of the shoulder at 0 degrees of abduction, resisted external rotation at 90 degrees of shoulder abduction, resisted serratus anterior wall slide, push-ups, and push-up plus.

Criteria to Progress to Phase 3: See Table 1a.

\section{PHASE 3: PLYOMETRIC PHASE}

This phase is a continuation of strength and proprioceptive goals with an increased focus on challenging the athlete with more complex dualattention tasks. This might include multiplanar balancing exercises while catching and throwing the ball with more graded perturbations to the trunk or stick.

Plyometrics can begin in this phase while monitoring the individual for signs and symptoms of joint effusion or pain. Plyometric progressions should develop gradually, advancing from double to single limb, simple to complex, challenging the athlete with different speeds, directions, and distance. Emphasis should be placed on demonstrating adequate deceleration control and shock attenuation. Once the athlete demonstrates adequate control with single limb plyometrics, exhibiting no signs of adverse response to the tibiofemoral or patellofemoral joints, and has achieved at least $80 \%$ on quadriceps limb symmetry index (LSI), a return to jogging progression can begin.

Upon completion of the return to jogging program, more applicable lacrosse-specific conditioning is appropriate. This includes linear change in direction drills emphasizing good deceleration mechanics and general conditioning to include increasing speed, duration, and distance of running. Lateral change in direction drills are also initiated, emphasizing good frontal and sagittal plane mechanics. Clinicians should monitor the athlete for dynamic changes in the trunk and lower extremity. The use of external cues such as a cone or piece of tape are helpful when coaching the athlete on how to change directions safely and effectively.

Late in this stage, the athlete can begin some restricted sport-specific activities. Wall ball (where the player throws and catches the ball against a wall) is permitted to incorporate skill development while reintroducing the necessary hand-eye coordination to return to the field. Similarly, the agility ladder can be utilized to foster footwork and speed. Passing and shooting are also cleared at this juncture and participation in non-contact drills as a stationary player passing and feeding the ball can be considered. Communication with the coach, athletic trainer, and parents is necessary to clearly articulate the athlete's restrictions.

It is important to note that while women's lacrosse is considered a non-contact sport, there is considerable incidental contact in the game. Clinicians unfamiliar with the sport should use extreme caution in this phase when clearing the athlete to participate in practice.

\section{Suggested Rehabilitation Program for Phase 3}

Strength Exercises:

These exercises continue to emphasize progressions in single leg strengthening to offset muscular imbalance identified on LSI testing. Rearfoot elevated split squats, traveling lunges with rotation, slide-board lateral lunges with a medicine ball press out, and single leg deadlift with resisted row are appropriate functional strengthening exercises. For higher-level collegiate and elite level athletes, barbell lifts can be incorporated at this interval including front squats, split squats, and trap bar deadlifts. When possible, consider adding unilateral loads to squats, deadlifts, and lunges to foster increased trunk control. 


\section{Lumbopelvic/Core Strengthening:}

These exercises should continue to incorporate the upper extremity when possible, to reproduce the power and explosiveness required for shooting and throwing. Side planks with a unilateral row, half kneeling chops, half kneeling lifts, and medicine ball power drills such as slam downs, overhead throws, and rainbows are recommended.

\section{Plyometric Exercises:}

Plyometric exercises include body weight jump squat, forward bound, and box jumps starting with eccentric bias jumping off the box. Assisted plyometrics using shuttle or assistance of super bands can assist in gradual progression of load. As neuromuscular control and confidence in the limb improves, double limb plyometrics can progress to traditional box jumps, depth jumps, and 90-degree jumps. Single limb plyometrics should follow a similar progression starting with single leg hop for height, single leg hop off a step focusing on deceleration control, and single leg hop for distance. Lateral hops should begin once single leg control improves, including lateral leaps and diagonal hopping from one limb to the other.

\begin{tabular}{c|cc}
$\begin{array}{c}\text { TABLE } \\
\text { Day }\end{array}$ & $\begin{array}{c}\text { Walk to Jog Ratio } \\
\text { (min) }\end{array}$ & $\begin{array}{c}\text { Progression } \\
\text { Total Time } \\
\text { (min) }\end{array}$ \\
\hline 1 & $4: 1$ & 20 \\
2 & Off & Off \\
3 & $3: 2$ & 20 \\
4 & Off & Off \\
5 & $2: 3$ & 20 \\
6 & Off & Off \\
7 & $1: 4$ & 20 \\
8 & Off & Off \\
9 & $1: 5$ & 25 \\
10 & Off & Off \\
11 & $1: 6$ & 30
\end{tabular}

\section{Return to Running Progression:}

See Table 2. Return to jogging progression must be completed on a level surface, at least 1 minute slower than pre-operative pace per mile. Monitor for signs and symptoms of adverse joint reaction, must have pain-free, symptom-free response to progress to next level. Athletes should be prepared to possibly repeat levels for several attempts before progressing.
Special Consideration with Plyometrics: At the beginning of Phase 3, impact activities should not be performed on consecutive days to avoid adverse joint response. As the athlete gradually increases the volume of impact activities and demonstrates no signs of adverse joint response, consecutive days are permitted. It is important for clinicians to carefully delineate the athlete's program, periodizing sets, repetitions, frequency, and duration in a calculated manner to adequately prepare the athlete for return to lacrosse. Please refer to Table $1 \mathrm{~b}$.

Cardiovascular:

Lacrosse-specific cardiovascular training can also begin, especially toward the later stages of this phase. Forward and backward running, shuffling, and middle-distance speed work such as 400 meters, 800 meters, and timed mile are appropriate.

Sport-Specific Activity:

Increased participation in practice is permitted under strict supervision such as passing and catching on the move, ground ball pick-ups, and some conditioning. The athlete is still not cleared to participate in drills involving change in direction or contact, including stick checking.

Throwing Program:

See Table 3.

Functional Movement Assessment/Return to Sport Testing:

Testing in this phase becomes more comprehensive. Limb symmetry strength testing should continue to be conducted every 4-6 weeks, monitoring the athlete's strength on both operative and non-operative limbs. Repeated neuromuscular control tests include the timed step-down test in addition to the timed lateral leap test, and the single leg hop tests.

The timed lateral leap test is a 60 -second test where the athlete hops laterally from one leg to the other. The length of the hop is measured to $60 \%$ of the athlete's height. The athlete is asked to hop to the beat of a metronome at 60 beats per minute (BPM). The single leg hop tests include the single leg hop for distance, triple hop, cross over hop, and the timed 6-meter hop. The distance traveled is measured and compared to the non-operative limb. These tests should also be periodically performed to evaluate the athlete's progress and to motivate the individual with regular reassessments. 
Table 1b. Rehabilitation Protocol

Phase 3

Phase 4

Phase 5

Frame

Criteria to

Progress

- Quadriceps LSI $>90 \%$

- Hip abductors LSI > 90\%

- Hamstring LSI $>80 / 90 \%$ (depending on graft site or concomitant procedures)

- Good neuromuscular control with 60

second timed step-down test

- Good landing mechanics with 60 second timed lateral leap and catch

- Good landing mechanics with single leg hop cluster (hop for distance, triple hop, crossover, $6 \mathrm{~m}$ timed) $>80 \%$ of uninvolved limb

Exercise

Recommendations

Cardiovascular

Recommendations

Pool Program

Water Jogging

strengthening from Phase 2

- Maintain ROM- no loss of extension, no

- Advanced plyometrics from double to single leg, from simple to complex

- Advance single leg perturbation training

- Linear change in direction drills

Lateral change in direction drills passing, shooting, wall ball)

- Lacrosse specific cardiovascular training

- Longer runs (20-30 minutes in duration)
5-7 months

- Quadriceps LSI > 90\%

- Hip abductors LSI >95\%

- Hamstring LSI > 95\%

- Good neuromuscular control with 60 -second timed step-down test

- Good landing mechanics with 60 - second timed lateral leap and catch

- Good landing mechanics with single leg hop cluster (hop for distance, triple hop, crossover, $6 \mathrm{~m}$ timed) $>90 \%$ of uninvolved limb

- Good acceleration, deceleration, change of direction control

- Ready to initiate controlled contact

- Ready to return to reduced lacrosse practice

- Running drills (straight line, zigzag, rotation, change in speed, change in direction) increased effusion

Lacrosse-specific drills (ladder drills,

- Interval Training

- Tempo Runs

- Fartleks

- Shuttle Runs

- Water Jogging

- Swimming can be used for non-impact cardiovascular training as deemed appropriate
7-9+ months

- Quadriceps LSI > 95\%

- Hip abductors LSI > 95\%

- Hamstring LSI > 95\%

Excellent neuromuscular control with 60-second timed step-down test

- Excellent landing mechanics with 60-second timed lateral leap and catch

- Excellent landing mechanics with single leg hop cluster (hop for distance, triple hop, crossover, $6 \mathrm{~m}$ timed) $>95 \%$ of uninvolved limb

- Excellent acceleration, deceleration, change of direction control

- Comfortable with all non-contact and controlled contact drills

- Participated in reduced lacrosse practice, completing final preparation for return to full contact lacrosse

- Initiate controlled contact lacrosse specific drills: contact drills, position specific training,

- Ball work drills with checking, picks, draw control, slides and crashing, offense/defense inside the 8 meters

Same as Phase 4

Swimming can be used for non-impact cardiovascular training as deemed appropriate 
TABLE 3. Lacrosse Skill Progression

Type of Activity

Examples

Phase 3 Throwing Program

Level 1: $\quad$ Passing and Catching Stationary

Jogging and Cradling

Level 2:

Passing and Catching

\section{Phase 4 Cutting/Pivoting}

\begin{tabular}{l|l} 
Level 3: & $\begin{array}{l}\text { Passing and Catching } \\
\text { on the Move } \\
\text { Parallel Passing }\end{array}$ \\
Level 4: & $\begin{array}{l}\text { Jogging and Cradling } \\
\text { with Change in Direction } \\
\text { Passing and Catching } \\
\text { with Pressure }\end{array}$ \\
Jogging and Cradling \\
with “Dummy Defense"
\end{tabular}

\section{Phase 5 Controlled Contact}

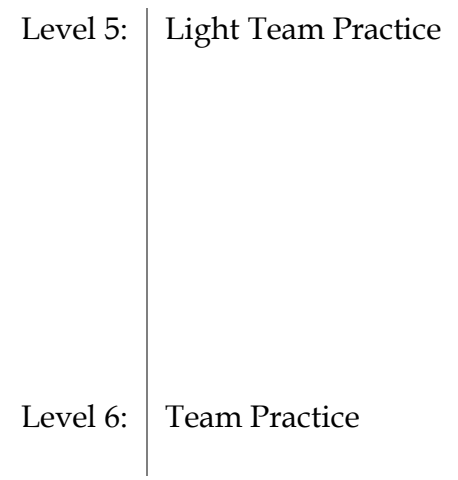

$50 \%$ effort

Stationary passing with partner

$50 \%$ speed, straight plane only

Full effort, Quick feet passing with partner

3 sets of 20 passes, 15 yards apart

3 sets of 20 passes, 30 yards apart

$50 \%$ speed: Shuttles with teammates, $\underline{C}$ cuts, $\underline{V}$ cuts, over the shoulder catches

$50 \%$ speed

3 sets to 50 -yard line and back

$50 \%$ speed, switching hands and dodging with a teammate, no checking $75 \%$ speed, top of the 8 meters to goal line extended, 3 sets of 5 repetitions

$50 \%$ speed, Defensive slides tracking ball movement

Full effort, passing and catching down the field with pressure

Full speed, switching hands and dodging with a teammate, no checking Full speed, top of the 8 meters to goal line extended, 3 sets of 5 repetitions

Full effort

Defensive slides with ball movement Defensive movement around the crease 1 vs. 1 shadowing teammate with light checking

Full speed running with cradling, change direction, under pressure Keep away with teammate inside the 8 meters with light checking 1 vs. 1 dodging drills with light checking Full speed shooting drills at various hash marks of the 8 meters, crease rolls

Full practice including team scrimmaging
3 sets of 20 passes, 15 yards apart 3 sets of 20 passes, 30 yards apart

5 sets of 50 yards

Stationary passing with partner 3 sets of 10 passes, 50 yards apart Passing Box Drill with quick feet

3 Person Weave Drill

Quick stick lateral shuffle partner passing, 3 sets of 15 yards and back

$75 \%$ speed

Run around the crease, alternating directions 3 sets of 5 repetitions

1 vs. 1 shadowing teammate, no checking

Ground ball pick-up, no checking

Full effort shuttles with teammates, 3 Person Weave Drill, Waterfall Drill, Star Drill

$75 \%$ speed

Run around the crease, alternating directions 3 sets of 5 repetitions

Ground ball pick-up with light checking

Practice goalie clears and midfield transitions up field

Participate in team practice with light checking Defense double teaming with light checking

Ground ball pick-up with coverage

Number advantages/disadvantages defensive slides and crashing inside the 8 meters 
Criteria to Progress to Phase 4: Quadriceps LSI $>90 \%$, hip abductor LSI >90\%, hamstring LSI > 80$90 \%$ are recommended to progress to Phase 4 . Neuromuscular control and endurance will continue to be assessed using the single leg lateral step-down test, the timed lateral leap test, and the single leg hop tests, monitoring for changes in the athlete's motor control. The athlete must have greater than $80 \%$ of the unaffected side with single leg hop testing to progress to Phase 4 . Of note, if the athlete achieves $80 \%$ or greater but does not demonstrate good neuromuscular control while performing these tests, the clinician should be advised not to progress the athlete to the next phase. The athlete should also be able to run continuously for 20-30 minutes without any increase in pain or effusion.

The athlete needs to be able to demonstrate safe and efficient acceleration and deceleration control with linear and lateral movements before starting Phase 4 progressions that include cutting and pivoting. If the athlete does meet these criteria, it is important for the clinician to identify these impairments and customize a treatment plan to adequately address these deficits.

\section{PHASE 4: CUTTING, PIVOTING, SKILL DEVELOPMENT}

In Phase 4, the athlete will continue to concentrate on functional strengthening but increased

emphasis is on performing more complex plyometric, agility, and conditioning activities. This phase introduces cutting and pivoting, altering several variables such as speed, direction, or resistance to further challenge the individual and prepare for game-like play. Single leg hops should become more challenging by increasing the volume, speed, and direction while conditioning should begin to emulate the stop-andgo demands of lacrosse. Non-contact lacrosse drills should be included, assessing movement through typical game-like scenarios such as passing and catching on the move, cutting and receiving the ball, ground ball pick-ups, and dodging defenders.

\section{Suggested Rehabilitation Program for Phase 4 Strength Exercises:}

Collaboration with a strength and conditioning specialist is always encouraged, particularly at this stage in rehabilitation. For college and elite level athletes, it is prudent for physical therapists and strength and conditioning specialists to discuss the athlete's preseason testing requirements and develop a program addressing the needs of the athlete.

Sport-Specific Activity:

Game-like drills are a critical element of rehabilitation in this phase. Reaction drills such mirroring another individual through various movements, sprinting to a ball drop, or cutting to numbered cones comprise movement fundamentals required for the sport. Box drills, cutting with a sports cord, drop step cutting, hopping in different directions, and hopping to a sprint are some examples of sport-specific plyometric and agility exercises that will prepare the athlete for the demands of her sport.

Cardiovascular Considerations:

High intensity interval training, tempo runs, fartleks, and shuttle runs starting with longer distances (50 yards) to shorter distances (10 yards) should be emphasized at this stage. Shuttle runs to the restraining line (30 yards) are important to replicate set offense and defense plays. Lacrosse specific non-contact drills such as dodging around cones: split dodge, roll dodge, stutter-step dodge should be included in conditioning.

Criteria to Progress to Phase 5: Quadriceps LSI $>95 \%$, hip abductor LSI > 95\%, hamstring LSI > $95 \%$ are recommended to progress to Phase 5 . All single leg hop tests should be $>90 \%$, exhibiting good takeoff and landing strategies, and all neuromuscular control tests detailed above should demonstrate excellent control. The individual should demonstrate good acceleration, deceleration, and the ability to cut and pivot off the affected and unaffected limb with confidence and control. It is recommended that a psychological return to readiness scale, such as the ACL-RSI scale, is utilized to identify any physiological barriers that may be present. This scale can be completed at subsequent strength/hop testing days, prior to completing the testing to measure progress, and so the results of testing do not influence the athlete's psychological readiness. The athlete should demonstrate willingness to initiate controlled contact and modified participation in supervised lacrosse practice.

\section{PHASE 5: CONTROLLED CONTACT/ RETURN TO PLAY}

Phase 5 includes the final preparation for return to lacrosse. The athlete continues to focus on 
functional strengthening, but rehabilitation centers its focus on merging plyometrics, agility, and conditioning to enhance lacrosse-specific training. This phase should introduce controlled contact during cutting and pivoting as well as position-specific training. Drills involving more indirect contact such as draw controls, stick checking, one-on-one play, and double teams should be simulated in therapy.

\section{Suggested Rehabilitation Program for Phase 5 Strength Exercises:}

The athlete should continue with a functional strengthening program. Continued collaboration with a strength and conditioning specialist is encouraged. College and elite level athletes may perform their strength program with their teams at this juncture. Olympic lifts such as the power clean, the dumbbell snatch, and the push jerk are appropriate to promote explosiveness and power. It is of the utmost importance that the entire rehabilitation team is in agreement about the athlete's comprehensive plan. Ultimately, this will instill trust in her rehabilitation team and prevent confusion regarding her current return-to-play status.

Sport-Specific Activity:

Controlled contact through various game-like play is appropriate in this phase. Stick checking and internal and external perturbations are appropriate to practice while the athlete changes direction. Ball movement drills with defender, jump balls, ground ball pick-ups with stick checking, receiving a pick while defending, slides and crashing should be practiced. This will increase the athlete's confidence and identify any reservations or aberrant movement strategies in the sport.

Criteria to Discharge to Return to Lacrosse: Individuals must maintain all Phase 4 criteria to progress and continue to demonstrate excellent neuromuscular control with functional movement testing. Individuals must demonstrate confidence and psychological readiness with lacrosse-specific activities and score $>90$ on ACLRSI questionnaire. An athlete must demonstrate good neuromuscular control with position-specific training, including ball movement with a defender, dodges with a defender, cradle with stick checking, the ability to pick and roll, defensive slides, inside the eight-meter crashing, and free position shooting and defending.

\section{SUMMARY}

The steady increase in women's lacrosse participation has led to an alarming rise in injury rates. ACL ruptures in this patient population have been increasing, having a detrimental effect on the athletic career of young players. Despite the rising injury rates in this population, there is a shortfall of research and guidance on returning to lacrosse after an injury.

There is evidence to suggest that rehabilitation for the female lacrosse player should differ from her male counterpart because the mechanism of ACL injury varies between genders. Anterior cruciate ligament injuries in high-school and college females were more commonly a result of non-contact play or overuse. $9,19,20$ These findings suggest that poor strength, endurance, and neuromuscular control may be plausible factors in the female risk for injury and that their rehabilitation program should reflect these discrepancies by addressing these deficits. Further research evaluating these gender-based protocols is necessary.

An exercise program for this population cannot solely be focused on attaining lower body strength and must be individualized to the athlete. Lumbopelvic and core stability is a key supplement for a sport that commands a great deal of rotatory control. Close attention to neuromuscular control and the overall quality of movements must be given as the athlete progresses from single leg strengthening to plyometrics, to agility, and eventually sport-specific activities. Ideally, the athlete is reintroduced to her sport in a gradual and purposeful manner. Criterion-based goals must be delineated and achieved before progressing to the next phase.

Communication among the athlete, physical therapist, coach, strength and conditioning team, and athletic trainer is imperative to allow a seamless transition from rehabilitation to the athlete's return to the field. This clinical commentary should serve as a guideline to those physical therapists who work with female lacrosse players. Further research is needed to better identify modifiable risk factors that contribute to the high injury rates and to address the specific needs for the female lacrosse player after an ACL reconstruction. 


\section{Conflict of Interest Statement}

The authors report no conflict of interest with the contents of this manuscript.

\section{Corresponding Author}

Rachel E. Lampros, PT, DPT, SCS, MS

Sports Medicine Physical Therapy

Massachusetts General Hospital

175 Cambridge St. $4^{\text {th }}$ Floor

Boston, Massachusetts 02114 USA

rlampros@mgh.harvard.edu

\section{REFERENCES}

1. Kvist J. Rehabilitation following anterior cruciate ligament injury: current recommendations for sports participation. Sports Med. 2004;34(4):269-80.

2. Davies GJ, McCarty E, Provencher M, Manske RC. ACL Return to sport guidelines and criteria. Curr Rev Musculoskelet Med. 2017;10(3):307-314.

3. Gokeler A, Welling W, Zaffagnini S, Seil R, Padua D. Development of a test battery to enhance safe return to sports after anterior cruciate ligament reconstruction. Knee Surg Sports Traumatol Arthrosc. 2017;25(1):192-199.

4. Rambaud AJM, Semay B, Samozino P, et al. Criteria for return to sport after anterior cruciate ligament reconstruction with lower reinjury risk (CR'STAL study): protocol for a prospective observational study in France. BMJ Open 2017;7:e015087.

5. Van Melick N, van Cingel RE, Brooijmans F, et al. Evidence-based clinical practice update: practice guidelines for anterior cruciate ligament rehabilitation based on a systematic review and multidisciplinary consensus. $\mathrm{Br}$ J Sports Med. 2016; 50:1506.

6. Bousquet BA, O'Brien L, Singleton S, Beggs M. Postoperative criterion based rehabilitation of ACL repairs: a clinical commentary. Int J Sports Phys Ther. 2018;13(2):293-305.

7. US Lacrosse. Participation report. US Lacrosse Organization website. Published 2018. Accessed January 15, 2021. https://www.uslacrosse.org/sites/default/files/pu blic/documents/about-us-lacrosse/2018participation-report.pdf

8. US Lacrosse. Girls' game overview. US Lacrosse Organization website. Published 2021. Accessed May $25,2021$.

9. https://www.usalacrosse.com/girls-game-overview 10. Vincent HK, Zdziarski LA, Vincent KR. Review of lacrosse-related musculoskeletal injuries in high school and collegiate players. Sports Health. 2015;7(5):448-51.
11. Barber Foss KD, Le Cara E, McCambridge T, Hinton RY, Kushner A, Myer GD. Epidemiology of injuries in women's lacrosse: implications for sport-, level-, and sex-specific injury prevention strategies. Clin J Sport Med. 2018;28(4):406-413.

12. Dick R, Lincoln A, Agel J, et al. Descriptive epidemiology of collegiate women's lacrosse injuries: National Collegiate Athletic Association Injury Surveillance System, 1988-1989 through 2003-2004. J Athl Train. 2007; 42: 262-9.

13. Dick R, Romani W, Agel J, et al. Descriptive epidemiology of collegiate men's lacrosse injuries: National Collegiate Athletic Association Injury Surveillance System, 1988-1989 through 2003-2004. J. Athl. Train. 2007; 42: 255-61.

14. Hinton R, Lincoln A, Almquist J, et al. Epidemiology of lacrosse injuries in high school-aged girls and boys. A 3-year prospective study. Am. J. Sports Med. 2005; 33: 1-11.

15. Hootman J, Dick R, Agel J. Epidemiology of collegiate injuries for 15 sports: summary and recommendations for injury prevention initiatives. $J$ Athl Train. 2007; 42: 311-9.

16. Agel J, Rockwood T, Klossner D. Collegiate ACL injury rates across 15 sports: National Collegiate Athletic Association injury surveillance system data update (2004-2005 Through 2012-2013). Clin J Sport Med. 2016 Nov;26(6):518-523.

17. Gornitzky AL, Lott A, Yellin JL, Fabricant PD, Lawrence JT, Ganley TJ. Sport-specific yearly risk and incidence of anterior cruciate ligament tears in high school athletes: a systematic review and metaanalysis. Am J Sports Med. 2016 Oct;44(10):2716-2723.

18. Pierpoint LA, Caswell SV, Walker N, et al. The first decade of web-based sports injury surveillance: descriptive epidemiology of injuries in US high school girls' lacrosse (2008-2009 through 2013-2014) and National Collegiate Athletic Association women's lacrosse (2004-2005 through 2013-2014). J Athl Train. 2019;54:42-54.

19. Kerr ZY, Lincoln AE, Caswell SV, Klossner DA, Walker N, Dompier TP. Epidemiology of National Collegiate Athletic Association women's lacrosse injuries, 2009-10 through 2014-15. J Sport Rehabil. 2018;27(2):118-125.

20. Warner K, Savage J, Kuenze CM, et al. A comparison of high school boys' and girls' lacrosse injuries: academic years 2008-2009 through 2015-2016. J Athl Train. 2018;53:1049-1055.

21. Carter EA, Westerman BJ, Lincoln AE, Hunting KL. Common game injury scenarios in men's and women's lacrosse. Int J Inj Contr Saf Promot. 2010;17(2):111-8.

22. Stanley LE, Kerr ZY, Dompier TP, Padua DA. Sex differences in the incidence of anterior cruciate ligament, medial collateral ligament, and meniscal injuries in collegiate and high school sports: 2009- 
2010 through 2013-2014. Am Sports Med. 2016; 44:1565-72.

23. Putukian M, Lincoln AE, Crisco JJ. Sports-specific issues in men's and women's lacrosse. Curr Sports Med Rep. 2014; 13: 334-340.

24. Renstrom P, Ljungqvist A, Arendt A, et al. Noncontact ACL injuries in female athletes: an International Olympic Committee current concepts statement. Br J Sports Med. 2008; 42: 394-412.

25. Mihata LC, Beutler AI, Boden BP. Comparing the incidence of anterior cruciate ligament injury in collegiate lacrosse, soccer and basketball players: implications for anterior cruciate ligament mechanism and prevention. Am J Sports Med. 2006; 34: 899-904.

26. Prodromos CC, Han Y, Rogowski J, et al. A metaanalysis of the incidence of anterior cruciate ligament tears as a function of gender, sport, and a knee injuryreduction regimen. Arthroscopy. 2007; 23: 1320-1325.

27. Czuppon S, Racette BA, Klein SE, Harris-Hayes M. Variables associated with return to sport following anterior cruciate ligament reconstruction: a systematic review. Br J Sports Med. 2014; 48:356.

28. Myer GD, Martin L Jr, Ford KR, Paterno MV, Schmitt LC, Heidt RS Jr, Colosimo A, Hewett TE. No association of time from surgery with functional deficits in athletes after anterior cruciate ligament reconstruction: evidence for objective return-to-sport criteria. Am J Sports Med. 2012; 40 (10):2256-63.

29. Barber-Westin SD, Noyes FR. Factors used to determine return to unrestricted sports activities after anterior cruciate ligament reconstruction. Arthroscopy. 2011; 27:1697-1705.

30. Logerstedt D, Di Stasi S, Grindem H, et al. Selfreported knee function can identify athletes who fail return-to-activity criteria up to 1 year after anterior cruciate ligament reconstruction: a Delaware-Oslo ACL cohort study. J Orthop Sports Phys The.2014;44:914-23.

31. Hartigan EH, Axe MJ, Snyder-Mackler L. Time line for noncopers to pass return-to-sports criteria after anterior cruciate ligament reconstruction. J Orthop Sports Phys Ther. 2010;40:141-54.

32. Risberg MA, Holm I, Myklebust G, Engebretsen L. Neuromuscular training versus strength training during first 6 months after anterior cruciate ligament reconstruction: a randomized clinical trial. Phys Ther. 2007; 87:737.

33. van Grinsven S, van Cingel RE, Holla CJ, van Loon CJ. Evidence-based rehabilitation following anterior cruciate ligament reconstruction. Knee Surg Sports Traumatol Arthrosc. 2010; 18:1128.

34. Bizzini M, Hancock D, Impellizzeri F. Suggestions from the field for return to sports participation following anterior cruciate ligament reconstruction: soccer. JOSPT. 2012 Apr;42(4):304-12.
35. Waters E. Suggestions from the field for return to sports participation following anterior cruciate ligament reconstruction: basketball. JOSPT. 2012 Apr;42(4):326-36.

36. Verstegen M, Falsone S, Orr R, Smith S. Suggestions from the field for return to sports participation following anterior cruciate ligament reconstruction: American football. JOSPT. 2012 Apr;42(4):337-44.

37. Kokmeyer D, Wahoff M, Mymern M. Suggestions from the field for return-to-sport rehabilitation following anterior cruciate ligament reconstruction: alpine skiing. JOSPT. 2012 Apr;42(4):313-25.

38. Vincent HK, Vincent KR. Core and back rehabilitation for high-speed rotation sports: highlight on lacrosse. Curr Sports Med Rep. 2018;17:208-214. 